\title{
Effects of Ethanol on Early Potassium Currents in Aplysia: Cell Specificity and Influence of Channel State
}

\author{
Steven N. Treistman and Andrew Wilson \\ Worcester Foundation for Experimental Biology, Shrewsbury, Massachusetts 01545
}

The effects of ethanol (EtOH) on the early potassium current, $I_{A}$, were examined in 3 identlited neurons of Aplysia using voltage-clamp techniques. The primary effect of EtOH on this current was a pronounced increase in the time constant of decay. However, this effect was cell specific, being evident in cells MCC and R15 but not in cell B1. Other parameters of $I_{\mathrm{A}}$ were not greatly affected in any of the cells, in comparison with the effects on decay time constant. Baseline parameters of $I_{A}$ were measured in each of the cells to determine whether subpopulations of $I_{A}$ channel might exist, and be differentially sensitive to EtOH. While differences did appear among cells, they were not consistent with an explanation of EtOH's actions based upon distribution of channel subtypes. The effect of EtOH on $I_{A}$ decay was dependent upon the voltage-clamp protocol used. When inactivation of $I_{\mathrm{A}}$ developed at $-20 \mathrm{mV}$, the slower development of inactivation noted above occurred. When inactivation without channel opening was produced by means of a prepulse to $-40 \mathrm{mV}$, EtOH speeded up the development of inactivation. A number of possible explanations for these findings are discussed. Most of the effects of EtOH occurred within 1 min of application of the drug, suggesting relatively rapid access to the site of action. Effects continued to develop over succeeding minutes. This slower-developing effect may reflect either a delayed access to channels due to slower diffusion into or lateral movement within the lipid phase of the membrane, or it may indicate that channels are accessible to the EtOH molecule only when in certain states.

Simple nervous systems, with their identified neurons, provide an ideal situation in which to examine the effects of ethanol $(\mathrm{EtOH})$ on the same current in different cells and different currents in the same cell. Because the aliphatic alcohols are simple molecules that act as anesthetics, they have been widely researched, and information on their physical chemistry and their actions on biological membranes is available and growing (e.g., Goldstein, 1985; Hunt, 1985). Combining this information with findings on the actions of the alcohols on voltage-dependent channels may help us to better understand mechanisms and modulators of channel function. Moreover, determination of the actions of $\mathrm{EtOH}$ on membrane channels may provide in-

\footnotetext{
Received Nov. 17, 1986; revised Mar. 9, 1987; accepted Apr. 8, 1987.

This work was supported by Grant AA05542 to S.N.T. from the Public Health Service. I would like to thank Drs. Justin Fallon, Patricia Camacho-Nasi, and Jose Lemos for comments on the manuscript.

Correspondence should be addressed to Steven N. Treistman, Worcester Foundation, 222 Maple Avenue, Shrewsbury, MA 01545.
}

Copyright (C) 1987 Society for Neuroscience $0270-6474 / 87 / 103207-08 \$ 02.00 / 0$ sights and experimental strategies to characterize and study the subset of neurons in complex nervous systems that are susceptible to EtOH. Pacemaker activity in Aplysia neurons is sensitive to high concentrations of EtOH (Silver and Treistman, 1982; Schwartz, 1985). In a previous paper, we determined the relative EtOH sensitivities of 4 voltage-dependent channel populations in Aplysia neurons (Camacho-Nasi and Treistman, 1986). In this paper, we describe differences in the effects of EtOH on $I_{\mathrm{A}}$ in 3 identified neurons in Aplysia. $I_{\mathrm{A}}$ is a transient outward potassium current that is inactivated at resting potential but is activated by membranc hypcrpolarization such as occurs during the afterhyperpolarization of the action potential. It acts to reduce the frequency of spiking (Connor and Stevens, 1971) and would be expected to influence pacemaker activity. In addition, we explore the effects of channel activity on the subsequent response to $\mathrm{EtOH}$. One of the most important unanswered questions in determining the mode of action for $\mathrm{EtOH}$ is whether the target is the protein channel or the lipid matrix in which the channels are imbedded (Franks and Lieb, 1986; Miller and Roth, 1986). A relationship between channel activity and the action of EtOH might indicate either some direct interaction with the channel or a more complex interaction with the lipids in the membrane than is often assumed in lipid theories of anesthesia. Finally, we examine the time course of EtOH's actions on $I_{\mathrm{A}}$.

\section{Materials and Methods}

Aplysia californica weighing between 50 and $100 \mathrm{gm}$ were obtained from the mariculture facilities at the Marine Biological Laboratory in Woods Hole, MA. The animals were maintained in artificial seawater (ASW; Instant Ocean, Aquarium Systems, Inc., Eastlake, $\mathrm{OH}$ ) at $15^{\circ} \mathrm{C}$. Experiments were performed on the metacerebral giant cell (MCC), the giant buccal cell (B1), and cell R15 in the abdominal ganglion. The results reported for cell B1 were also seen in cell B2 (for cell nomenclature, see Frazier et al., 1967; Gardner, 1971; Weiss et al., 1978). Ganglia were desheathed by microdissection over the cell to be penetrated. Axotomy of the cell was performed by cutting the axon 150-300 $\mu \mathrm{m}$ from the cell body in order to obtain an optimal space-clamp of the cell. Success of the axotomy was verified in voltage clamp by the loss of the late, fast transient currents arising from unclamped axon (Treistman, 1980). The ganglion was pinned to the Sylgard-covered bottom of a flow chamber that allowed superfusion with different solutions. Chamber volume was $5 \mathrm{ml}$, and flow rates allowed the turnover of $5 \mathrm{ml}$ of solution in $3 \mathrm{~min}$.

Selected cells were impaled with 2 shielded microelectrodes (Smith et al., 1980), one for recording membrane potential and the other to pass current. Electrodes had resistances between 1 and $4 \mathrm{M} \Omega$ (measured in ASW) and were filled with $3 \mathrm{M} \mathrm{KCl}$. Membrane voltage was measured differentially with respect to an extracellular electrode independent of bath ground. The voltage-clamp unit used in these experiments (Dagan Corp., model 8500) was extensively modified in order to achieve a shorter settling time. In the worst cases, the current trace was $95 \%$ settled within $750 \mu$ sec.

Correction for leakage was made using a $\mathrm{P} / 2$ procedure (Bezanilla 

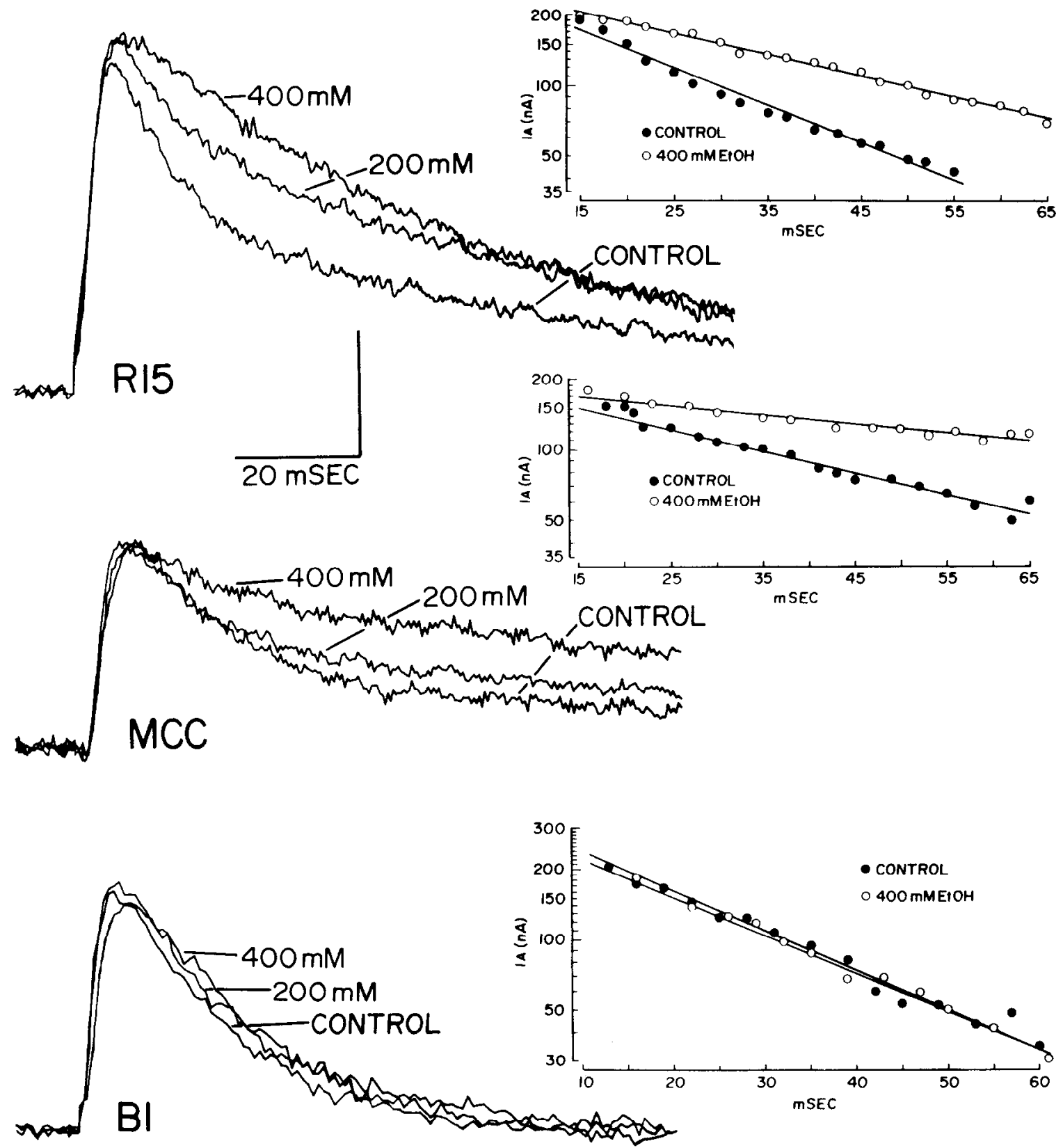

Figure 1. Effects of EtOH on $I_{\mathrm{A}}$ in 3 identified neurons. $I_{\mathrm{A}}$ is elicited by a step to $-20 \mathrm{mV}$ from a holding potential of $-70 \mathrm{mV}$. Competing currents are pharmacologically blocked, as described in Materials and Methods. The decay of current is significantly prolonged by EtOH, in a concentration-dependent manner in MCC and R15, while EtOH has little effect on the decay of $I_{\mathrm{A}}$ in B1. Semilogarithmic plots of the current decay are shown at right in each panel. The lines drawn through the data points are the theoretical values for the computed regression line. Although not evident, since only a portion of the traces is shown, currents returned to baseline values in all cases. Vertical bar, $150 \mathrm{nA}$ for MCC and $75 \mathrm{nA}$ for R15 and B1 traces.

and Armstrong, 1977). Data were digitized every $100 \mu \mathrm{sec}$ and stored on a PDP 11 computer for analysis off-line. After digitization and appropriate scaling, the corresponding current records were algebraically added to correct for leakage. The computer was programmed to establish the magnitude of the peak current, the time to peak current, and the time constant of current decay. The decay time constant was computed by linear regression using the method of least squares. Multiexponential decay of $I_{\mathrm{A}}$ in Aplysia neurons has been reported (Strong, 1984). We observed a multiexponential decay of $I_{\mathrm{A}}$ on occasion but did not use these cells for this study. We also discarded cells in which $I_{\mathrm{A}}$ did not decay to baseline levels. In the vast majority of cases the $r^{2}$ value of the linear regression was greater than 0.99 and was never less than 0.98 for the decay of $I_{\mathrm{A}}$ during the $100 \mathrm{msec}$ following the peak. All experiments were performed at room temperature $\left(\sim 20^{\circ} \mathrm{C}\right.$. $)$. Data are presented as mean values \pm SEM.

The composition of the ASW was (in $\mathrm{mM}$ ): $460 \mathrm{NaCl}, 10 \mathrm{KCl}, 11$ $\mathrm{CaCl}_{2}, 55 \mathrm{MgCl}_{2}, 10$ Tris $\mathrm{HCl}$, adjusted to $\mathrm{pH} 7.8$. To study $I_{\mathrm{A}}$ in isolation from competing currents, the sodium in ASW was replaced with equimolar tetramethylammonium (TMA) to eliminate sodium currents. Inward calcium currents and outward potassium currents were blocked by adding $125 \mu \mathrm{M}$ cadmium chloride and $70 \mathrm{~mm}$ tetraethylammonium chloride (TEA) to the perfusion medium. Series resistance was not compensated, but the maximum error expected for the $I_{\mathrm{A}}$ observed (series resistance value of $10^{4} \Omega$ used for computation; Adams and Gage, 1979) was $2.5 \mathrm{mV}$. EtOH effects reported in this paper could not be accounted for by series resistance error. 


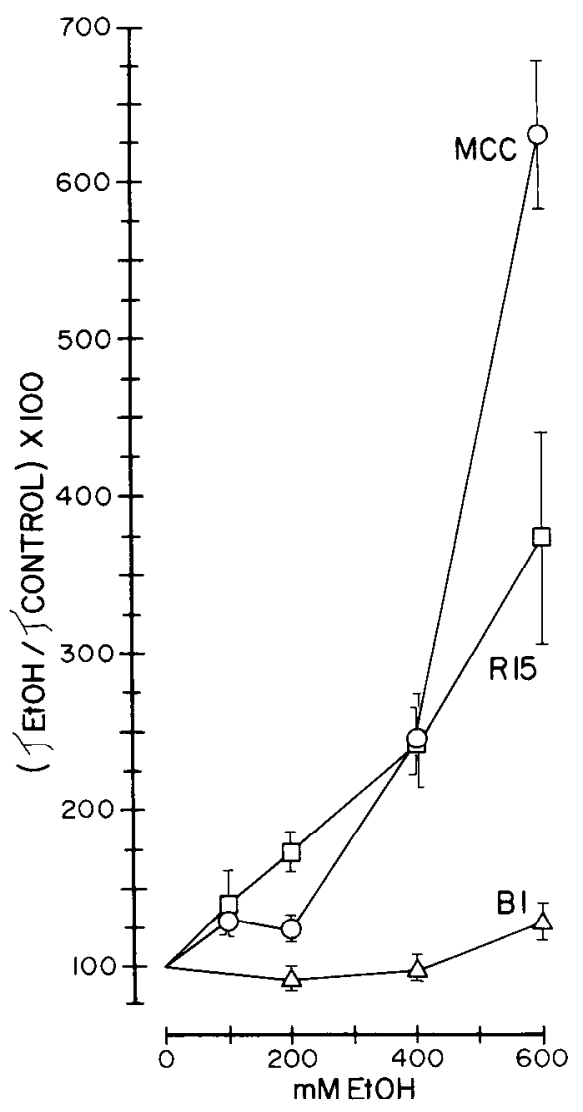

Figure 2. Plots of the mean change in decay time constant of $I_{\mathrm{A}}$ as a function of $\mathrm{EtOH}$ concentration. The means were obtained by averaging the data from all the experiments with each identified neuron at a given concentration of EtOH. Bars in this and all other plots represent \pm SEM.

\section{Results}

Differences in EtOH sensitivity of $\mathrm{I}_{A}$ decay in identified cells

Striking differences in the response of $I_{\mathrm{A}}$ to similar EtOH concentrations were observed when the MCC and R15 were compared with the large buccal ganglion neuron, B1. Current traces from individual experiments, as well as semilogarithmic plots of the decay of current are shown in Figure 1. The primary response to EtOH in MCC and R15 was a concentration-dependent increase in the decay time constant of $I_{\mathrm{A}}$. This increase in decay kinetics was obvious at $200 \mathrm{~mm}$ EtOH and was very pronounced at $400 \mathrm{mM}$ concentrations. The effect was highly reproducible, and an increase in the decay kinetics of $I_{\mathrm{A}}$ at $\mathrm{EtOH}$ concentrations above $200 \mathrm{mM}$ was evident in every $\mathrm{MCC}(n=$ 12 ) and R15 ( $n=11)$ examined. At the same EtOH concentrations, the decay kinetics of $I_{\mathrm{A}}$ in $\mathrm{B} 1(n=15)$ were largely unaffected. The decay of $I_{\mathrm{A}}$ can usually be fitted by a single exponential (Camacho-Nasi and Treistman, 1986). Figure 2 shows plots of the decay time constant of $I_{\mathrm{A}}$ obtained by averaging the values obtained in $\mathrm{MCC}, \mathrm{R} 15$, and $\mathrm{Bl}$ as a function of $\mathrm{EtOH}$ concentration. All of the effects seen in the presence of $\mathrm{EtOH}$ concentrations up to $400 \mathrm{mM}$ were completely reversible after washout of the drug. At higher concentrations the degree of reversibility became more variable, ranging from 50 to $100 \%$ recovery of control values. An explanation of the results by osmotic effects of EtOH is unlikcly since control cxperiments to test this possibility (Silver and Treistman, 1982; Schwartz,

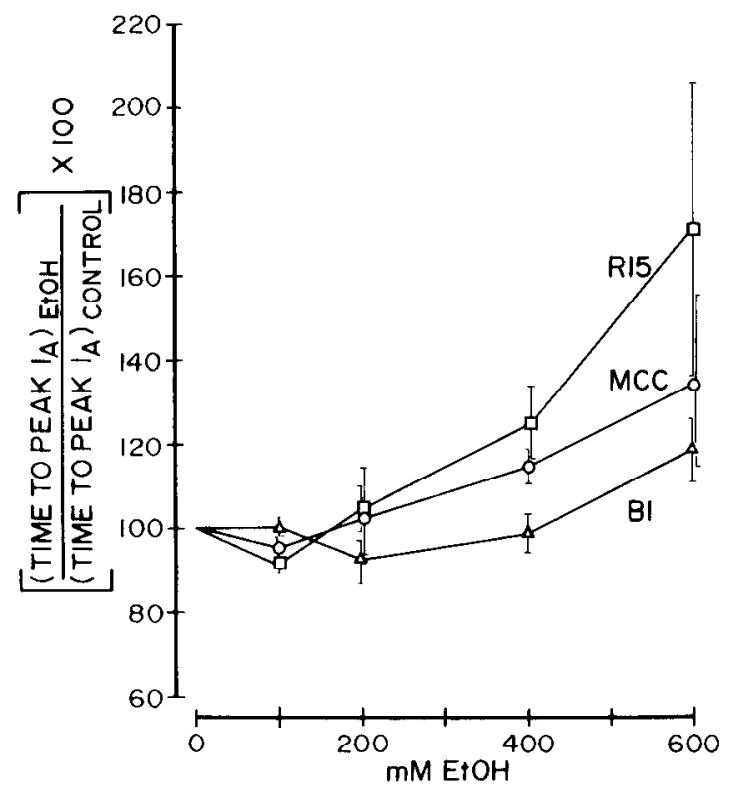

Figure 3. Plots of the mean change in time to peak $I_{\mathrm{A}}$ in each of the 3 cells examined, as a function of EtOH concentration. Data were averaged from all experiments with each identified neuron at a given concentration of EtOH.

1985) indicated that even at high concentrations EtOH was not affecting electrophysiology by this mechanism.

Other parameters of $I_{\mathrm{A}}$ were not as consistently or as dramatically affected as the decay kinetics in MCC and R15.

\section{Time-to-peak $\mathrm{I}_{A}$ amplitude}

This parameter showed a weak effect of $\mathrm{EtOH}$ at concentrations of $400 \mathrm{~mm}$ and greater, with the the time-to-peak $I_{\mathrm{A}}$ increasing with increasing EtOH concentrations in both R15 and MCC. A similar trend was evident in the buccal cells, although it was smaller than the effects seen in the other 2 cells. Data averaged from these experiments are plotted in Figure 3.

\section{Voltage dependency of inactivation}

$I_{\mathrm{A}}$ is inactivated at holding potentials more depolarized than the resting potential of the cell (Connor and Stevens, 1971). The voltage dependency of inactivation was determined by giving a $500 \mathrm{msec}$ prepulse to voltages between -90 and $-50 \mathrm{mV}$, in $5 \mathrm{mV}$ increments. Each prepulse was followed by a test pulse to $-20 \mathrm{mV}$, during which $I_{\mathrm{A}}$ was measured. $I_{\mathrm{A}}$, as expected, became smaller as the prepulse became more depolarized. The voltage dependence of inactivation was only weakly affected by EtOH. In all 3 cells, there was a small initial shift in the depolarizing direction of the steady-state inactivation curve. After this initial shift in $200 \mathrm{~mm}$ EtOH, changes in voltage dependency were not consistent and were not progressively greater with increasing EtOH concentrations. Graphs of the inactivation curves as a function of EtOH concentration for the 3 cells are shown in Figure $4, A-C$. In Figure $4 D$, the mean voltage at which $50 \%$ inactivation occurred is plotted as a function of $\mathrm{EtOH}$ concentration for all 3 cells.

\section{Voltage dependency of activation}

We were unable to make a rigorous study of the voltage dependence of activation because contaminating currents were often evident at levels more depolarized than $-15 \mathrm{mV}$. For the sake 

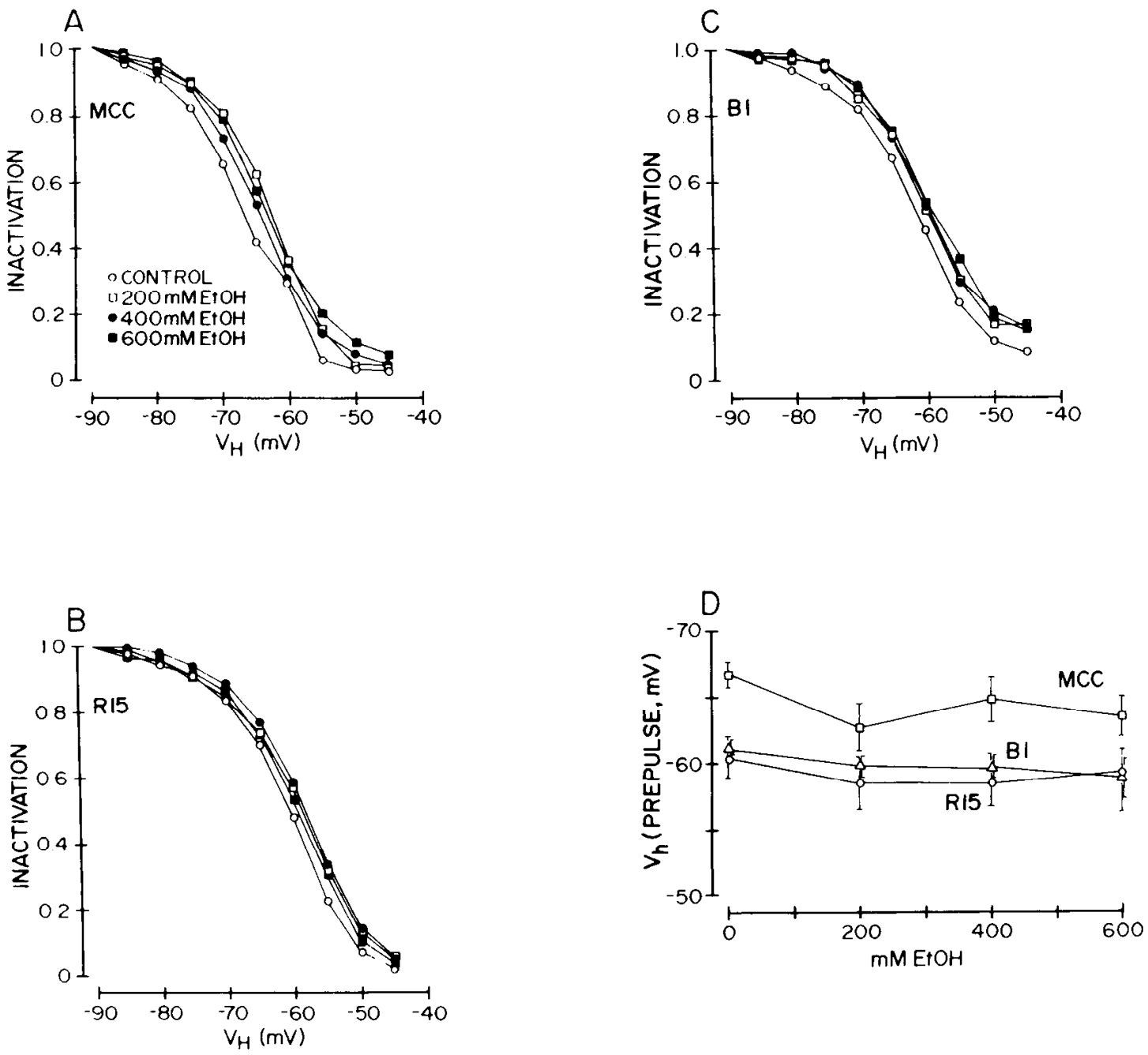

Figure 4. Voltage dependency of $I_{\mathrm{A}}$ inactivation in the presence of EtOH. $A-C$, The degree of inactivation was determined by measuring $I_{\mathrm{A}}$ amplitude as a function of holding potential ( $V_{H} ; 500 \mathrm{msec}$ prepulse) in each of the 3 cells exposed to EtOH concentrations as noted. Command potential was to $-20 \mathrm{mV}$. D, Plot of the holding potential (prepulse potential) at which $50 \%$ inactivation of $I_{\mathrm{A}}$ occurred in each of the 3 cells as a function of EtOH concentration.

of comparison, we normalized $I_{\mathrm{A}}$ during progressively larger clamp steps in increments of $5 \mathrm{mV}$ between -50 and $-25 \mathrm{mV}$ to $I_{\mathrm{A}}$ at $-20 \mathrm{mV}$ in $\mathrm{B} 1$, or $-15 \mathrm{mV}$ in $\mathrm{MCC}$ and $\mathrm{R} 15$, and plotted these values as a function of EtOH concentration. When the data were plotted in this fashion (Fig. 5), EtOH had no apparent effect on the voltage dependence of activation in any of the 3 cells. Although large-scale changes would be apparent in this analysis, the normalization procedure is clearly not completely valid since $I_{\mathrm{A}}$ grows significantly as depolarization is extended beyond the $-15 \mathrm{mV}$ level, and we have no indication of $I_{\mathrm{A}}$ magnitude among cells and at various alcohol concentrations at higher voltages.

\section{Amplitude}

Both R15 and MCC showed an increase in the amplitude of $I_{\mathrm{A}}$ on occasion, which became more pronounced as the $\mathrm{EtOH}$ concentration increased from 100 to $600 \mathrm{~mm}$. This was most apparent in R15, where it occurred in about half of the cells ex-

Table 1. Baseline parameters for $I_{A}$

MCC

Decay time constant (msec)

Time-to-peak $I_{\mathrm{A}}$ (msec)

$50 \%$ inactivation (prepulse potential; $\mathrm{mV}$ )

$50 \%$ activation (command voltage; $\mathrm{mV})^{a}$

Amplitude at $-20 \mathrm{mV}$ (nA)

$\begin{aligned} 20.6 & \pm 0.8 \quad(29) \\ 7.7 & \pm 0.3(29) \\ 68.0 & \pm 0.6(25) \\ -26.4 & \pm 0.4(10) \\ 277.8 & \pm 19.4(29)\end{aligned}$

B1

$32.2 \pm 3.6(24)$
$10.8 \pm 0.6(24)$
$62.9 \pm 0.5(22)$
$-24.0 \pm 0.6(11)$
$151.5 \pm 8.6(20)$

R15

$30.9 \pm 2.3(16)$

$9.7 \pm 0.6 \quad(16)$

$60.1 \pm 0.8$ (14)

$-25.0 \pm 0.6 \quad(9)$

$218.1 \pm 20.3(14)$

${ }^{a}$ See text for normalization procedure used. Numbers in parentheses are number of measurements. 

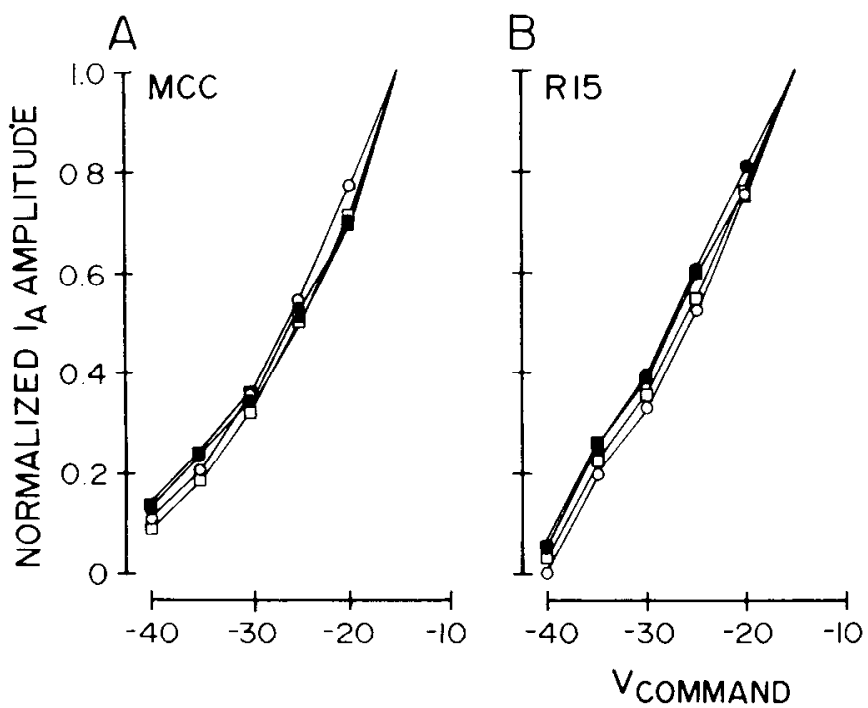

amined. Although the increase in amplitude was small when averaged over all cells, in the most pronounced instances it constituted a $20 \%$ increase in peak amplitude at a $400 \mathrm{~mm}$ concentration of EtOH. EtOH never decreased $I_{\mathrm{A}}$ amplitude in either MCC or R15. In the buccal cells, $I_{\mathrm{A}}$ did not show large changes in amplitude when exposed to EtOH. When $I_{\mathrm{A}}$ amplitude was affected in this cell, it was most frequently reduced slightly (Fig. 6).

\section{Baseline parameters for $\mathrm{I}_{A}$}

Baseline (control) values for each of the $I_{\mathrm{A}}$ parameters studied in the 3 cells were carefully examined to determine whether there were differences that might indicate different subpopulations of $I_{\mathrm{A}}$ which could account for the cell-specific differences in $\mathrm{EtOH}$ sensitivity. The data already presented include only experiments in which the cell was carried through the entire series of EtOH concentrations. To examine baseline values we expanded the pool of cells to include those from experiments aborted before EtOH data were collected. The data are shown in Table 1. Some differences are apparent among the cells studied, and interpretations of these differences are examined in the Discussion.

\section{Specific nature of the $\mathrm{I}_{A}$ EtOH insensitivity in BI}

The insensitivity of $\mathrm{Bl}$ to $\mathrm{EtOH}$ is not a reflection of a generalized insensitivity in this cell. The response to EtOH of the delayed rectifier, $I_{\mathrm{K}}$, was twice tested in $\mathrm{Bl}$, and it showed a $20 \%$ increase in amplitude (Camacho-Nasi, personal communication), which is within the range of values seen in other cells (Camacho-Nasi and Treistman, 1986). Inward sodium currents in B1 were also affected by EtOH similarly to other cells (unpublished observations). The buccal ganglion was not notably different from other ganglia with respect to the $\mathrm{EtOH}$ sensitivity of $I_{\mathrm{A}}$ in cells other than B1 and B2. When tested, the large motoneurons of the buccal ganglion (Gardner, 1971) had $I_{\mathrm{A}}$ sensitivities to $\mathrm{EtOH}$ that were similar to those seen in $\mathrm{MCC}$ and R15.

\section{Double-pulse voltage-clamp experiments}

These experiments were designed to determine whether the effects of EtOH on the inactivation kinetics of $I_{\mathrm{A}}$ were dependent upon activation of the $I_{\mathrm{A}}$ channels. The prolongation of $I_{\mathrm{A}}$ decay

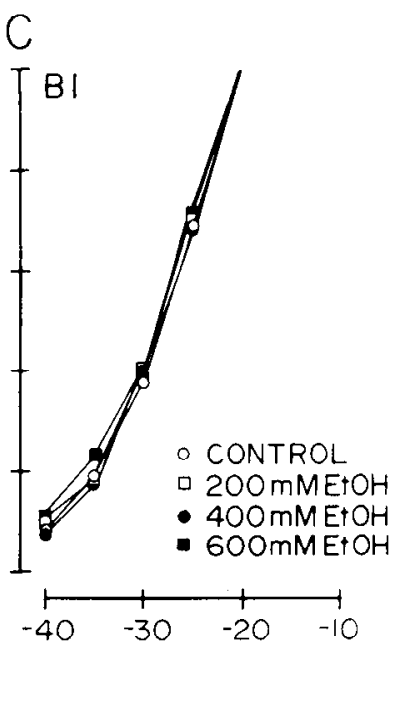

Figure 5. $A-C$, Plots of $I_{\mathrm{A}}$ amplitude at specified command potential, normalized to $I_{\mathrm{A}}$ amplitude at $-15 \mathrm{mV}$ (MCC and R15) or $-20 \mathrm{mV}$ (B1). A range of $\mathrm{FtOH}$ concentrations is shown for each of the 3 cells. EtOH had little effect on this parameter. previously described was obtained with currents flowing during steps to $-20 \mathrm{mV}$, where a population of $I_{\mathrm{A}}$ channels is open. To examine EtOH's effects on inactivation of $I_{\mathrm{A}}$ when these channels were not open, the cell was stepped to $-40 \mathrm{mV}$ for increasing lengths of time from a holding potential of $-70 \mathrm{mV}$. The $-40 \mathrm{mV}$ prepulse was followed immediately by a step to $-20 \mathrm{mV}$ to activate $I_{\mathrm{A}}$. At $-40 \mathrm{mV}$, we saw no evidence of the activation of $I_{\mathrm{A}}$ channels. The amplitude of $I_{\mathrm{A}}$ activated during the step to $-20 \mathrm{mV}$ decreased as the duration of the $-40 \mathrm{mV}$ prepulse increased, indicating the development of time-dependent inactivation. The effects of $\mathrm{EtOH}$ on $I_{\mathrm{A}}$ are very different with this double-pulse protocol, compared with the single-pulse protocol. The experimental paradigm, and results of single experiments in MCC and B1 are shown in Figure 7. Instead of slowing the inactivation of $I_{\mathrm{A}}$ in $\mathrm{MCC}, \mathrm{EtOH}$ now speeds up

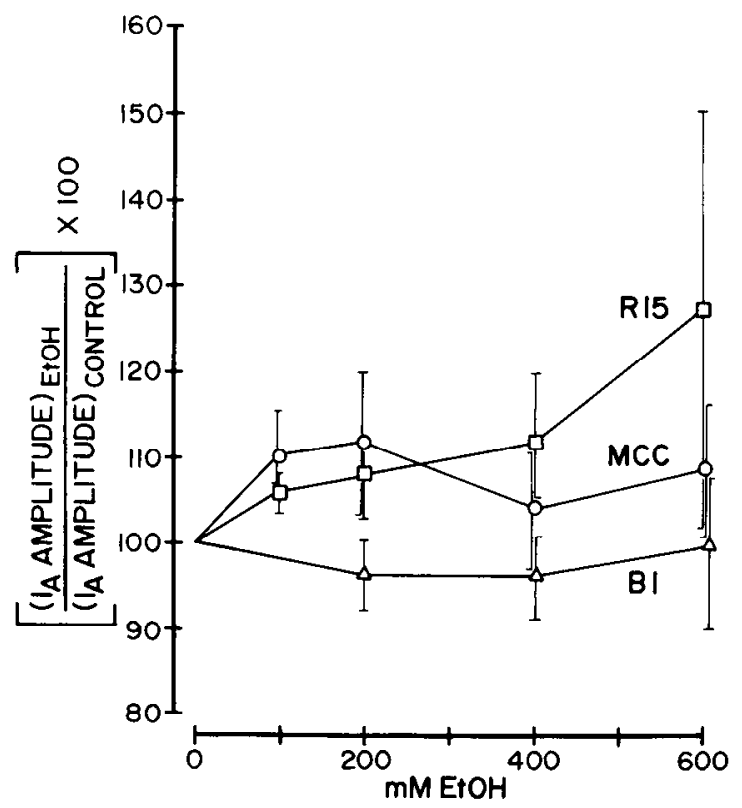

Figure 6. Plots of the mean change in $I_{\mathrm{A}}$ amplitude in each of the 3 cells examined as a function of $\mathrm{EtOH}$ concentration. Data were averaged from all experiments with each of the identified neurons at a given EtOH concentration. 


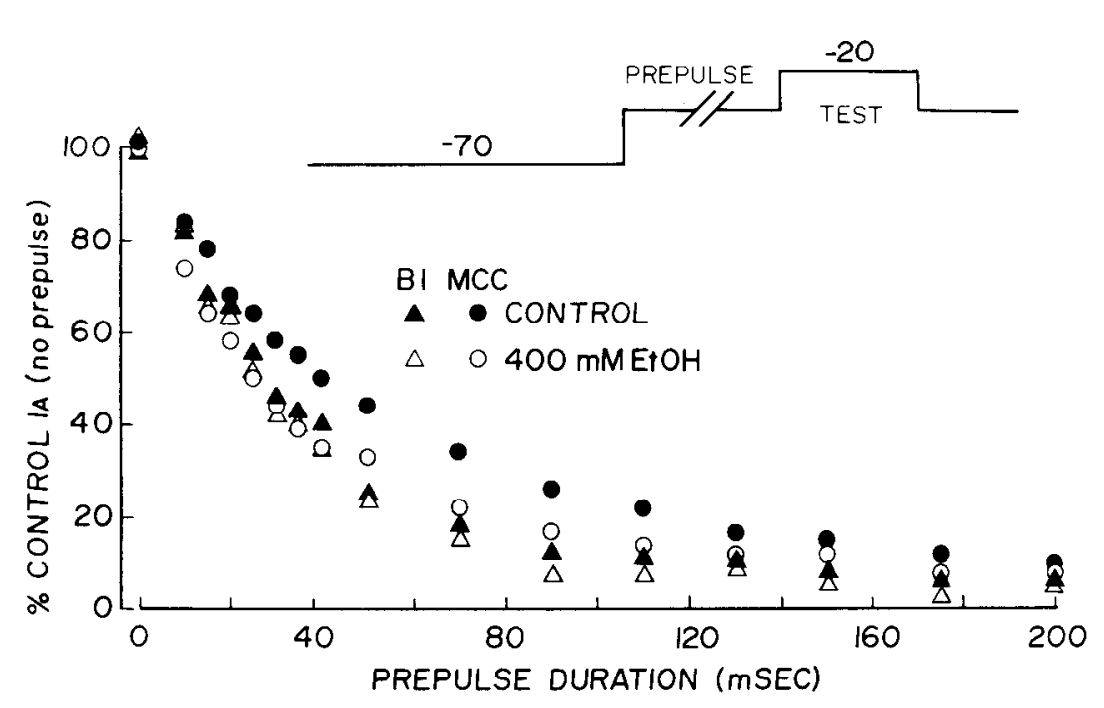

Figure 7. Effect of EtOH on $I_{\mathrm{A}}$ amplitude during a test pulse to $-20 \mathrm{mV}$, immediately after a prepulse of varying duration, to $-40 \mathrm{mV}$. The voltage protocol is shown in the inset. Data are from individual experiments with $\mathrm{B} 1$ and MCC. For both cells, inactivation increases with prepulses of increasing duration, and EtOH causes an enhanced inactivation; i.e., a shorter duration prepulse produces a greater reduction in the $I_{\mathrm{A}}$ activated during the test pulse. the development of inactivation. In other words, a shorter prepulse produces a greater degree of inactivation in the presence of $\mathrm{EtOH}$. This was the result in each of the 3 experiments where this protocol was used in MCC. Single-pulse protocols interspersed with the double-pulse protocols showed the same increase of decay time constant previously noted with the simpler protocol. The percentage change in inactivation kinetics produced by similar EtOH concentrations in MCC was considerably less when using the $-40 \mathrm{mV}$ prepulse protocol than for the $-20 \mathrm{mV}$ single-pulse protocol. Results very similar to those seen in the MCC were seen in all cells in which the prepulse protocol was tested, including 2 R15s and one L3 cell. Once again, for each of these cells, single-pulse protocols were interspersed with the prepulse protocols and showed that, in the presence of EtOH, the decay of $I_{\mathrm{A}}$ was slowed during the singlepulse protocol, whereas a nonactivating prepulse of given du-

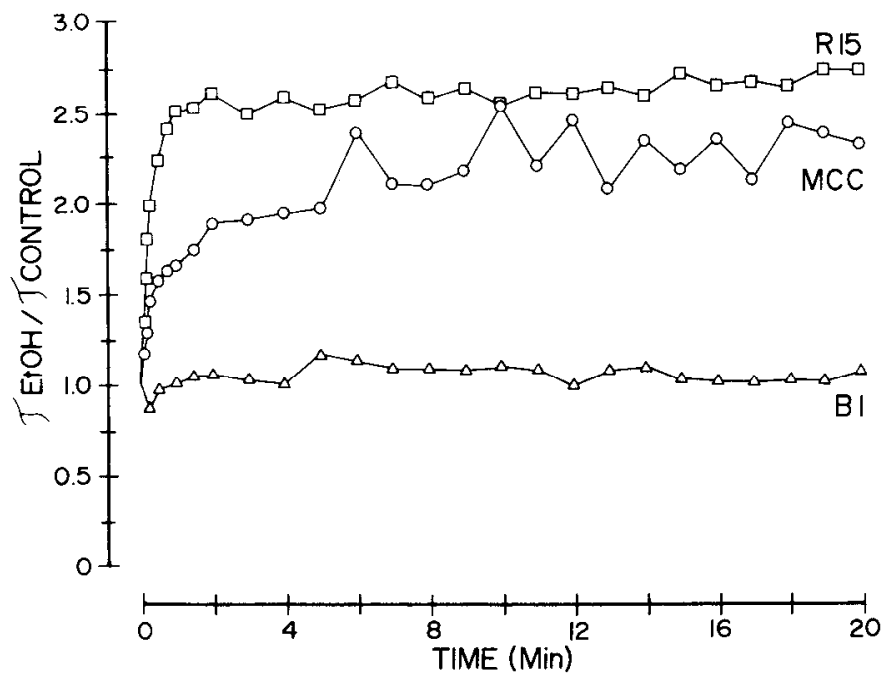

Figure 8. Decay time constant of $I_{\mathrm{A}}$ as a function of time after exposure to $\mathrm{EtOH}$ in the 3 cells examined. EtOH was added directly to the bath by pipette, accompanied by agitation of the bath to promote mixing, to give a final concentration of $300 \mathrm{~mm}$. In a number of experiments, the ganglion was treated with protease (Type IV, Sigma) for $30 \mathrm{~min}$ at $37^{\circ} \mathrm{C}$ to remove any adherent glial cells and then washed extensively in ASW at room temperature. Protease treatment did not affect the time course of EtOH action. The decay time constant of $I_{\mathrm{A}}$ in $\mathrm{Bl}$ is essentially unaffected by EtOH. ration produced a greater degree of inactivation. EtOH did not cause a measurable change in the kinetics of inactivation produced by a prepuise, in B1.

\section{Time course of EtOH action}

In order to determine the time course over which the effects of EtOH develop, $I_{\mathrm{A}}$ in $\mathrm{MCC}(n=4), \mathrm{R} 15(n=5)$, and B1 $(n=$ 3) was monitored after the sudden introduction of EtOH to give a bath concentration of $300 \mathrm{~mm}$. Figure 8 shows the decay time constant in an MCC, an R15, and a B1 as a function of time after introduction of $\mathrm{EtOH}$. These results are representative of those seen in all the experiments that examined time course. In both MCC and R15, approximately $50 \%$ of the increase in decay time constant was achieved within the first 30 sec of the introduction of EtOH. The time constant continued to grow at a slower rate after this, reaching steady-state values within about 10 min. The R 15 represented in Figure 8 was pronase-treated, as described in the figure legend, to remove adherent tissue that might impede access to the bare cell membrane. Cells treated in this manner did not differ from untreated cells with respect to the effects of EtOH or the time course during which those effects developed. The data also make it clear that $\mathrm{B} 1$ does not undergo a transient change in decay time constant in the presence of $\mathrm{EtOH}$, which might go undetected at the later observation times.

\section{Discussion}

High concentrations of EtOH have a strong, but reversible effect on the pacemaker activity patterns of neurons, without significant effects on the resting potential of the cells (Silver and Treistman, 1982). Bursting pacemaker activity is very complex, involving a number of conductances and possibly metabolic control (Chaplain and Kramer, 1976; Treistman and Levitan, 1976; Drake and Treistman, 1981), and insights into the mechanisms underlying channel function that might be facilitated by using $\mathrm{EtOH}$ are more easily obtained by studying individual voltage-dependent conductances. $I_{\mathrm{A}}$ is an important current in determining the temporal characteristics of spike production such as bursting pacemaker activity.

We have prevoiusly reported consistent differences in the sensitivity of various voltage-gated currents to EtOH (CamachoNasi and Treistman, 1986). In this paper, we describe some of 
the actions of $\mathrm{EtOH}$ on $I_{\mathrm{A}}$, the early transient potassium current, and we present data indicating that for $I_{\mathrm{A}}$ there are clear-cut differences in the sensitivity to $\mathrm{EtOH}$ in different cells within the Aplysia nervous system. In the majority of cells we examined, represented in this paper by $\mathrm{R} 15$ and $\mathrm{MCC}, I_{\mathrm{A}}$ responds to EtOH primarily by a prolongation of the decay phase of the current, most likely representing a slowdown of the inactivation process. Insensitive cells, represented by $\mathrm{B} 1$ and $\mathrm{B} 2$, have an $I_{\mathrm{A}}$ in which inactivation is almost completely unaffected by $\mathrm{EtOH}$ at the same concentrations. However, the same buccal cells do not differ from other cells with respect to the EtOH sensitivity of other currents such as $I_{\mathrm{K}}$ and $I_{\mathrm{Na}}$. We may, therefore, assume that $\mathrm{EtOH}$ is able to gain access to the membrane of the insensitive cells. There is some suggestion in the single-pulse protocol data that $\mathrm{Bl}$ is responding to $600 \mathrm{~mm} \mathrm{EtOH}$ as MCC and R15 do at much lower concentrations, but this is not completely clear, and it is not possible to raise the EtOH concentrations above $600 \mathrm{~mm}$ because irreversible cell damage begins to appear at higher concentrations.

The cell-specific nature of EtOH's actions on $I_{\mathrm{A}}$ could arise in 3 situations: (1) the same type of $I_{\mathrm{A}}$ channel could be present in all cells, but the lipid environment could differ, leading to different sensitivities to EtOH. This explanation would be compatible with a large body of literature pointing to a lipid target for the alcohol molecule. (2) Different subclasses of $I_{\mathrm{A}}$ channel could reside in similar lipid environments, with the subclasses exhibiting different EtOH sensitivities. (3) Related to possibility 2 , the same channel unit could exist in the same lipid environment in different cells but could be modified by other mechanisms, such as changes in phosphorylation state or intracellular calcium concentrations. The EtOH sensitivity of $I_{\mathrm{A}}$ in different cells would then reflect the distribution of modulated channels. The differential sensitivity that would result from such a scheme could be due either to differences in the propensity of a given channel to be modulated or to the variable presence or sensitivity of a modulatory second messenger system within different neurons. There is, in fact, evidence that $I_{\mathrm{A}}$ can be modified by neurochemical factors and intracellular calcium (Alkon, 1984; Levitan, 1985; Weight, 1985). We cannot rule out the possibiity that the effects of EtOH on $I_{\mathrm{A}}$ are due to the release of a transmitter substance or other neuroactive agent, despite the presence of $\mathrm{Cd}^{2+}$ in our medium. This possibility could be addressed by examination of isolated neurons in culture, but we have not yet performed such experiments.

$\mathrm{EtOH}$ has selective effects upon the diffusibility of fluorescent lipid analogs in Aplysia neuronal membranes. For example, probes that differ from each other with respect to phospholipid head group are affected by EtOH differently (Treistman et al., 1987). These, and other results (Wolf, 1983), suggest that the lipid structure of the membrane is a heterogeneous distribution of microdomains. A segregation of channel types among these domains, with selective access by different alochols could provide an explanation for the selectivity of EtOH's actions on different types of channel. It does not address how cell-specific differences such as those described in this paper arise. Such an explanation might be found by comparing the diffusibility of probes among identified cells, but such a study has not yet been done. The fact that of 4 channel types we studied, only $I_{\mathrm{A}}$ shows cell specificity (Camacho-Nasi and Treistman, 1986), might indicate that, if differences in lipid environment occur, they involve subsets of lipids associated with particular channels, rather than bulk lipid differences.
A number of the measured parameters of the macroscopic $I_{\mathrm{A}}$ vary among the 3 cells, suggesting that subpopulations of $I_{\mathrm{A}}$ channel may exist. One prominent difference that appeared was in the $I_{\mathrm{A}}$ decay time constant of the MCC and buccal neurons. While this finding may reflect $I_{\mathrm{A}}$ subpopulations, it is unlikely to underlie the differences in EtOH sensitivity since $I_{\mathrm{A}}$ in cell $\mathrm{R} 15$, which is sensitive, has a baseline decay time constant much closer to that of the buccal cells than it is to that of MCC. The voltage at which $50 \%$ steady-state activation occurred was also different for MCC and the buccal cells, but once again, the values for the buccal cells were very similar to those for R15, making this an unlikely basis for differences in sensitivity. Differences in average amplitude of $I_{\mathrm{A}}$ in the 3 cell types are probably attributable to the differences in membrane area, since the buccal cells are the smallest of the 3 types. A detailed correlation was not attempted because extensive infolding of the cell membrane makes a simple analysis based on diameter questionable. While the baseline data do not rule out the possibility that there are subpopulations of $I_{\mathrm{A}}$ channel, they do make it unlikely that such differences cause the dichotomy between sensitive and insensitive cells.

Differences in the effects of EtOH on $I_{\mathrm{A}}$ channels inactivated at $-40 \mathrm{mV}$ versus channels inactivated at $-20 \mathrm{mV}$ indicate that the "state" of a channel may affect the action of EtOH. A number of possibilities could explain this. The most intriguing is that an open channel presents a different target for EtOH than a channel that inactivates without ever opening. The resulting access would allow EtOH to prolong the current decay. This interpretation is not easily compatible with a bulk lipid effect secondarily affecting $I_{\mathrm{A}}$ channels. In the case of certain local anesthetics, the blockade of the sodium channel is facilitated by depolarizing prepulses, and this has been attributed to increased access to the blocking sitc as a function of channel opening (Ych, 1978). We have found a small degree of use dependence in the response of $I_{\mathrm{Ca}}$ in Aplysia cells to EtOH (Camacho-Nasi and Treistman, 1987). This dependence is present when calcium is the charge carrier but not when barium carries the current through calcium channels. When barium is the charge carrier, inactivation is largely absent. This result suggests that channel history influences EtOH's actions via the inactivation component of the calcium channel. This is interesting in light of the fact that, for $I_{\mathrm{A}}$, it is inactivation of the current that is most sensitive to EtOH.

Alternatives to the open channel theory presented above could also explain our results. Inactivation at $-40 \mathrm{mV}$ might be mechanistically different from that at $-20 \mathrm{mV}$, with $\mathrm{EtOH}$ affecting the 2 inactivation processes differently. If this is the case, then both inactivation processes show similar cell specificity in their EtOH sensitivity.

The data indicate that although most of the effects of EtOH on $I_{\mathrm{A}}$ are complete within the first minute of exposure, the response continues to develop during succeeding minutes. The initial effect suggests a relatively unresticted access to the channel, either directy or via adjacent lipids. The slower-developing phase of action could reflect a less direct route of access, such as might result from slower entry into or slower lateral diffusion within the membrane until channel targets are encountered. Alternatively, it may indicate that a particular conformation of the channel is necessary for EtOH to exert its effects. If a number of conformational "states" are possible, then a significant lag time could be observed before channel modification by EtOH would occur. Such a situation seems to be the case for the action 
of anesthetics on the ACh receptor (Miller et al., 1986). Our data suggesting that inactivation of an open channel is affected by EtOH differently than inactivation of a closed channel is consistent with this type of kinetic scheme. Finally, the more slowly developing effects could be due to actions on enzyme systems affecting the kinetics of $I_{\mathrm{A}}$.

In Aplysia, calcium currents are more sensitive than are $I_{\mathrm{A}}$ to EtOH (Camacho-Nasi and Treistman, 1986) and would have to be considered, in this model system, to be the primary target for the clinical manifestations of alcohol. The EtOH concentrations used for most of the $I_{\mathrm{A}}$ studies in this paper are 2-10 times greater than those which have been reported to be lethal in humans (American Medical Association, 1968). However, $I_{\text {A }}$ plays a critical role in the temporal patterning of action potential production (Connor and Stevens, 1971), and even a small percentage change in its time course could have significant effects upon neural activity. Since the cells that underlie the actions of EtOH in the brain presumably are a subset of the entire cell population, our finding of cell specificity in the actions of $\mathrm{EtOH}$ on $I_{\mathrm{A}}$ are potentially important. The dependence of EtOH's actions upon membrane potential, and the apparent sensitivity of the inactivation portion of the current for both $I_{\mathrm{A}}$ and $I_{\mathrm{Ca}}$ may also prove to be important in understanding the basis for alcohol's actions on nerve cells and the mechanisms controlling channel function.

\section{References}

Adams, D. J., and P. W. Gage (1979) Ionic currents in response to depolarization in an Aplysia neurone. J. Physiol. (Lond.) 289: 115141.

Alkon, D. L. (1984) Calcium-mediated reduction of ionic currents: A biophysical memory trace. Science 226: 1037-1045.

American Medical Association (1968) Alcohol and the Impaired Driver: A Manual on the Medicolegal Aspects of Chemical Tests for Intoxication.

Bezanilla, F., and C. M. Armstrong (1977) Inactivation of the sodium channel. I. Sodium current experiments. J'. Gen. Physiol. 70: 549566.

Camacho-Nasi, P., and S. N. Treistman (1986) Ethanol effects on voltage-dependent membrane conductances. Comparative sensitivities of channel populations in Aplysia neurons. Cell. Mol. Neurobiol. 6: 263-279.

Camacho-Nasi, P., and S. N. Treistman (1987) Ethanol-induced reduction of neuronal calcium current in Aplysia: An examination of possible mechanisms. Cell. Mol. Neurobiol. (in press).

Chaplain, R. A., and G. Kramer (1976) The effect of glutamate on beating pacemaker neurons isolated from the abdominal ganglion of Aplysia californica. Brain Res. 101: 141-147.

Connor, J. A., and C. F. Stevens (1971) Voltage clamp studies of a transient outward membrane current in gastropod neural somata. J. Physiol. (Lond.) 213: 21-30.

Drakc, P. F., and S. N. Treistman (1981) Mechanisms of action of cyclic nucleotides on a bursting pacemaker and a silent neuron in Aplysia. Brain Res. 218: 243-254.

Franks, N. P., and W. R. Lieb (1986) Do protein/anesthetic interactions underlie the mechanism of general anesthesia? In Molecular and Cellular Mechanisms of Anesthetics, K. Miller and S. Roth, eds., Plenum, New York.

Frazier, W. T., E. R. Kandel, I. Kupfermann, R. Waziri, and R. E. Coggeshall (1967) Morphological and functional properties of identified cells in the abdominal ganglion of Aplysia californica. J. Neurophysiol. 30: 1288-1351.

Gardner, D. (1971) Bilateral symmetry and interneuronal organization in the buccal ganglion of Aplysia. Science 173: 550-553.

Goldstein, D. B. (1985) Alcohol and cellular membranes. In Alcohol and the Developing Brain, U. Rydberg et al., eds., Raven Press, New York.

Hunt, W. A. (1985) Alcohol and Biological Membranes, Guilford Press, New York.

Levitan, I. B. (1985) Phosphorylation of ion channels. J. Membr. Biol. 87: $177-190$.

Miller, K. W., and S. H. Roth (1986) Inside the black box. In Molecular and Cellular Mechanisms of Anesthetics, K. Miller and S. Roth, eds., pp. 261-266, Plenum, New York.

Miller, K. W., L. M. Braswell, L. L. Firestone, B. A. Dodson, and S. A. Forman (1986) General anesthetics act both specifically and nonspecifically on acetylcholine receptors. In Molecular and Cellular Mechanisms of Anesthetics, K. Miller and S. Roth, eds., pp. 125-137, Plenum, New York.

Schwartz, M. H. (1985) Effect of ethanol on subthreshold currents of Aplysia pacemaker neurons. Brain Res. 332: 337-353.

Silver, L. H., and S. N. Treistman (1982) Effects of alcohols on pacemaker activity in neurons of Aplysia californica. Cell. Mol. Neurobiol. 2: $215-226$.

Smith, T. J., J. L. Barker, B. M. Smith, and T. R. Coburn (1980) Voltage clamping with microelectrodes. J. Neurosci. Methods 3: 105128.

Strong, J. A. (1984) Modulation of potassium current kinetics in bag cell neurons of Aplysia by an activator of adenylate cyclase. J. Neurosci. 4: 2772-2783.

Treistman, S. N. (1980) Axonal site for impulse initiation and rhythmogenesis in Aplysia pacemaker neurons. Brain Res. 187: 201-205.

Treistman, S. N., and I. B. Levitan (1976) Alteration of electrical activity in molluscan neurones by cyclic nucleotides and peptide factors. Nature 261: 62-64.

Treistman, S. N., M. Moynahan, and D. E. Wolf (1987) Influence of alcohols, temperature, and region on the mobility of lipids in neuronal membrane. Biochim. Biophys. Acta. 898: 109-120.

Weight, F. F. (1985) Transient voltage and calcium-dependent outward currents in hippocampal CA-3 pyramidal neurons. J. Neurophysiol. 53: 1038-1058.

Weiss, K. R., J. Cohen, and I. Kupfermann (1978) Modulatory control of buccal mass musculature by a serotinergic neurone (metacerebral cell) in Aplysia. J. Neurophysiol. 41: 181-203.

Wolf, D. E. (1983) The plasma membrane in early mammalian development. In Development of Mammals, vol. 5, M. H. Johnson, ed., pp. 187-208, Elsevier/N. Holland Biomedical Press, Amsterdam.

Yeh, J.Z. (1978) Sodium inactivation mechanism modulates QX-314 block of sodium channels in squid giant axons. Biophys. J. 24: 569574. 